\title{
Incidence and Prevalence of Sexual Dysfunction in Infertile Females
}

\author{
S AGGARWAL ROHINA ${ }^{1}, V^{\text {MISHRA VINEET }}{ }^{2}$, A PANCHAL NAVIN ${ }^{3}$, H PATEL NITAL $^{4}, V^{2}$ \\ DESHCHOUGULE VRUSHALI ${ }^{5}, \mathrm{~F} \mathrm{JASANI} \mathrm{ANIL}^{6}$
}

\begin{abstract}
:
Introduction: The sexual response in women is complex. The association of infertility and sexual dysfunction is overlapping.

Objective: To find the incidence and prevalence of female sexual dysfunction in infertile females and its correlation with infertility.

Material and Methods:Total of 500 patients in the age group of 24-42 years participated in the prospective study. They were assigned fertile and infertile group. Female sexual dysfunction was assessed according to FSFI questionnaire. Patients with past history of any psychiatric illness, endocrinological disorder e.g. diabetes mellitus or on antihypertensive treatment were excluded.

In our study 170 (63.67\%) patients in the infertile group ( $n=267)$ had female sexual dysfunction as compared to108 (46.35\%) in the fertile group ( $n=233)$, which is statistically significant $(P$ 0.0001 ). Most common dysfunction observed was arousal (70\%) in infertile patients. Common dysfunctions observed in fertile females were desire(40\%) and orgasm(40\%). FSD was significantly higher in infertile females of 31-37 years age group ( $P$ 0.002), while more common in fertile females of $>42$ years age $(P<0.0001)$. Higher female sexual dysfunction was observed in illiterate infertile females ( $P$ 0.039). Amongst the pathological factors endometriosis was the statistically significant factor associated with female sexual dysfunction and infertility ( $P$ $<0.0001)$. No significant correlation in duration of infertility or type of infertility was observed with female sexual dysfunction.
\end{abstract}

Conclusions: Female sexual dysfunction as the cause or the effect should be ascertained in infertility.

Keywords: Female sexual dysfunction, Fertile and Infertile Females, The female sexual functioning index (FSFI) Questionnaire

\section{Introduction:}

The sexual response in women is complex and incompletely understood and has been reconceptualised as a cyclic process that emphasizes sociocultural taboos and physical factors. It is mediated by psychological/, environmental and physiological factors e.g. hormonal, vascular, muscular, neurological, age or pathological factors such as urological, gynecological, surgical or medical conditions. Sexual dysfunction may be sometimes a healthy adaptive response to adverse condition in the interpersonal relationship.
Types of sexual disorders that are common in females include:

I. Sexual desire disorder

2. Sexual arousal disorder

3. Orgasmic disorder

4. Sexual pain disorders (vaginismus, dyspareunia)

FSD has multiple overlapping risk factors eg.

Biological: endometriosis, premature ovarian failure, medications

Social: relationship stress, pressures to conceive, religion

1. Assistant Professor

2. Professor and Head of the Department

3,4. Junior Lecturer,

5,6. Clinical Fellow 
Psychological: depression, anxiety, low self-esteem

Any diversions from normal sexual response will lead to female sexual dysfunction, hence distress and agony. In 1999 National health and social life survey reported that $43.0 \%$ of American women were suffering from sexual problems in the preceding year. Infertility has a greater effect on psychosexual behavior and quality of life of a woman. Sexual dysfunction may be the cause and affect the relationship resulting in infertility, or it may be incidental to infertility. Psychosexual interventions should be a part of the evaluation and treatment of infertile couple.

Despite the importance of these issues to their health care, many women find it difficult to talk to the physician about sexual difficulties encountered and many physicians are uncomfortable discussing such issues with their patients. Gynecologists should pay more attention to this important issue and encourage patients to have an evaluation by a psychiatrist or psychologist.

\section{Materials and Methods:}

A total of 500 women, attending the O.P.D of Obstetrics and Gynecology department of Institute of Kidney Disease and Research Centre, in the age group of $24-42$ years, from March 2009 to March 2010 were recruited for the prospective study.

The subjects volunteered as participants after the purpose of study was explained to them and their consents were signed. All of the educated women filled the questionnaires (Female sexual function index) by themselves and illiterate women were interviewed personally. The questionnaires were in all three languages i.e. Hindi, English and Gujarati. Infertility status such as duration and type of infertility, age, educational status were noted. Patients with past history of any psychiatric illness, endocrinological disorder antihypertensive treatment were excluded from the study.

The female sexual functioning index: FSFI is a brief, multidimensional scale for assessing sexual function in women. Higher score indicates better sexual function. The questionnaire consists of 19 questions covering 6 domains-Desire (2 questions), Arousal, Lubrication (4 questions-each), Orgasm, Satisfaction, pain (3 questions each). Response to each question relates to previous month and are scored either from 0 (no sexual activity), 1 (indicative of dysfunction) to 5 (suggestive of normal sexual activity). Individual domain scores are obtained by adding the scores of the individual questions that comprise the domain and multiplying the sum by the domain factor provided in the FSFI for each domain. The full scale scores were obtained by adding the 6 domain score. The minimal score possible is 2 and the maximum is 36 . The cut off score to demarcate sexual dysfunction is 26.55 , as obtained from a validation study. Accordingly scores less than 4.28, 5.08, 5.45, 5.05, 5.04, and 5.51 on the desire, arousal, and lubrication. Orgasm, satisfaction and pain domain respectively were used to classify participants with such dysfunction reliably.

Results:

Table-I

Total population $=500$

\begin{tabular}{lcc}
\hline FSD & Infertile Group $(\mathrm{n}=267)(53.4 \%)$ & Fertile Group(n=233) $(46.6 \%)$ \\
\hline FSD - Present & $170(63.67 \%)^{\star}$ & $108(46.35 \%)^{\star}$ \\
Mean FSFI score & $17.8 \pm 6.26$ & $17.85 \pm 5.38$ \\
FSD - Absent & $97(36.37 \%)$ & $125(53.64 \%)$ \\
Mean FSFI score & $27.07 \pm 1.58$ & $26.79 \pm 1.16$ \\
\hline
\end{tabular}

*P-Value 0.0001

Table-II

Domains of FSD in infertile group and fertile group

\begin{tabular}{lccc}
\hline & Infertile Group $(\mathrm{n}=170)$ & Fertile Group $(\mathrm{n}=108)$ & P-Value \\
\hline Desire & $33(19 \%)$ & $44(40 \%)$ & $<0.0001$ \\
Arousal & $119(70 \%)$ & $38(35 \%)$ & $<0.0001$ \\
Lubrication & $110(65 \%)$ & $27(25 \%)$ & $<0.0001$ \\
Orgasm & $31(18 \%)$ & $44(40 \%)$ & 0.00004 \\
Satisfaction & $60(35 \%)$ & $41(38 \%)$ & 0.652 \\
Pain & $100(58.8 \%)$ & $40(37 \%)$ & 0.0001 \\
Vaginismus & $25(25 \%)$ & $16(40 \%)$ & 0.078 \\
Dyspareunia & $50(50 \%)$ & $04(10 \%)$ & 0.00001 \\
Nonspecific & $25(25 \%)$ & $20(50 \%)$ & 0.004 \\
\hline
\end{tabular}


Table-III

Age wise distribution of FSD in infertile and fertile group

\begin{tabular}{lccc}
\hline Interval of Age & $\begin{array}{c}\text { FSD PresentInfertile } \\
\text { Group }(n=170)\end{array}$ & $\begin{array}{c}\text { FSD PresentFertile } \\
\text { Group }(n=108)\end{array}$ & P-Value \\
\hline$<24$ Yrs & $38(22.3 \%)$ & $20(18.5 \%)$ & 0.443 \\
$24-30$ Yrs & $58(34.1 \%)$ & $25(23.3 \%)$ & 0.057 \\
$31-37$ Yrs & $51(30 \%)$ & $15(14 \%)$ & 0.002 \\
$38-42$ Yrs & $7(4.1 \%)$ & $10(9.3 \%)$ & 0.077 \\
$>42$ Yrs & $16(9.4 \%)$ & $38(35.1 \%)$ & $<0.0001$ \\
\hline
\end{tabular}

Table-IV

Education Status in Infertile and Fertile Females

\begin{tabular}{|c|c|c|c|c|c|c|}
\hline & \multicolumn{3}{|c|}{ Infertile Group } & \multicolumn{3}{|c|}{ Fertile Group } \\
\hline & $\begin{array}{c}\text { FSD Present } \\
(n=170)\end{array}$ & $\begin{array}{c}\text { FSDAbsent } \\
(n=97)\end{array}$ & $\overline{\text { P-Value }}$ & $\begin{array}{c}\text { FSD Present } \\
(n=108)\end{array}$ & $\begin{array}{c}\text { FSDAbsent } \\
(n=125)\end{array}$ & P-Value \\
\hline Illiterate & $11(6.47 \%)$ & $01(1.03 \%)$ & 0.039 & $10(9.2 \%)$ & $3(2.4 \%)$ & 0.023 \\
\hline Primary & $04(2.35)$ & $02(2.06 \%)$ & 0.877 & $3(2.77 \%)$ & $3(2.4 \%)$ & 0.856 \\
\hline Matrics & 79 (46.4\%) & $39(40.2 \%)$ & 0.322 & $50(46.2 \%)$ & $57(45.6 \%)$ & 0.915 \\
\hline Higher Secondary & $39(22.9 \%)$ & $30(30.9 \%)$ & 0.152 & $19(17.5 \%)$ & $27(21.6 \%)$ & 0.443 \\
\hline Graduate & $34(20 \%)$ & $24(24.7 \%)$ & 0.366 & $22(20.3 \%)$ & $31(24.8 \%)$ & 0.421 \\
\hline Post Graduate & $3(1.76 \%)$ & $01(1.03 \%)$ & 0.355 & $4(3.7 \%)$ & $4(3.2 \%)$ & 0.833 \\
\hline
\end{tabular}

Table-V

Pathological factors

\begin{tabular}{lccc}
\hline Factors & FSD Present(n=170) & FSD Present $(\mathrm{n}=108)$ & P-value \\
\hline POF & $21(12 \%)$ & $22(20 \%)$ & 0.071 \\
Endometriosis & $68(40 \%)$ & $11(10 \%)$ & $<0.0001$ \\
Tubal/PID & $60(35 \%)$ & $33(30 \%)$ & 0.414 \\
Unexplained & $09(05 \%)$ & $33(30 \%)$ & $<0.0001$ \\
PCOD & $14(08 \%)$ & $11(10 \%)$ & 0.579 \\
\hline
\end{tabular}

Statistical analysis was performed using the Statistical Package for the Social Sciences

(SPSS version 12.0). Continuous variables were compared using Student T-test.

Chi square test \& Fisher exact test were used to assess the effect of change in different categorical variables. Data values are expressed as mean $\pm S D$, count (\%age) \& $P<0.05$ is considered to be statistically significant.

\section{Discussion:}

Infertility may alter a women sexual expression by causing or exacerbating sexual problems as a consequence of the diagnosis, investigation and treatment of infertility. Conversely sexual problems may contribute to infertility. In women, sexual stimuli alone do not necessarily lead to sexual arousal because psychological factors may prevent their processing. Studies have shown that infertility has a significantly greater effect on women's sense of sexual identity than do other sources of stress. Women may also experience marital distress following the diagnosis of infertility with multiple, unsuccessful treatment attempts and hence result in FSD. The focus of coitus becomes solely on conception rather than of pleasure. The act of timed sexual intercourse is a rec-ognized risk factor for the development of situational sexual dysfunction in both men and women and. loss of a couple's intimacy. Therefore, male partners of an infertile couple may also develop sexual dysfunction following the diagno-sis. In addition, women may suffer from this trend if their male partner has sexual difficulties such as erectile dysfunction or premature ejaculation. Various drugs used in infertility 
treatment e.g. GnRH analogues Clomiphene citrate (CC). Metformin. Oral contraceptives (OCs) commonly used for ovulation induction, may affect any aspect of the female sexual response cycle due to its side effects, Side effects may include decreased libido and dyspareu-nia secondary to vaginal dryness.

In this study out of 500 patients, 267 (53.4\%) were suffering from infertility while $233(46.6 \%)$ were fertile couples. Out of infertile females $63.67 \%$ patients had FSD as compared to $46.35 \%$ of fertile females, which is statistically significant (P 0.0001)[Table1]. Most common sexual dysfunction was arousal dysfunction (70\%) in infertile couples (P 0.0001), while desire (40\%) (P 0.0001) and orgasmic (40\%)(P 0.00004) dysfunction were the dysfunctions encountered in the fertile group [Table2] .

In infertile group, between 31 to 37 years of age, 51 (30\%) of patients had sexual dysfunction as compared to $15(14 \%)$ in the fertile group (P 0.002) which is statistically significant [Table3]. On the other hand, in the fertile group, patients of $>42$ years of age had significant sexual dysfunction $(P<0.0001)$ [Table3].

Demographic data as regards to duration of marriage or infertility or type of infertility in infertile group with FSD present or absent were similar. FSD was more common in infertile illiterate and fertile illiterate females, which is statistically significant [Table4]. Illiteracy is an independent risk factor associated with female sexual dysfunction.

Amongst pathological factors endometriosis was commonly observed in the infertile patients (40\%) with FSD present $(P<0.0001)$ [Table 5]. Endo-metriosis ${ }^{1}$ is also one of the most com-mon causes of chronic pelvic pain and deep dyspareunia in women, due to the presence of inflammation in the pelvis, adnexal masses, or adhesions. This type of pain during vaginal penetration can limit sexual activity and potentially lead to sexual avoidance.

.Naeimeh Tayebi ${ }^{2}$ et al in (2009)-has reported most common sexual problems in infertile females were anorgasmia (83.7\%) and decreased libido (80.7\%). Jindal ${ }^{3}$ et al (1996)- has shown decreased frequency of intercourse and anorgasmia were the most common problems identified. Audu's ${ }^{4}$ study on 97 Nigerian infertile females showed that the prevalence of arousal disorder and dyspareunia was $20.6 \%$ and $57.7 \%$ respectively. Jain and associates ${ }^{5}$ observed dyspareunia, decreased libido and orgasmic failure were the most common dysfunctions. Posnholzer ${ }^{6}$ et al - showed that the prevalence of pain disorders were more in the age group of $20-39 \mathrm{yrs}$, and FSD prevalence increased with increasing age of women.

Preexisting FSD may be a causal fac-tor in infertility by contributing to lim-ited or absent sexual activity. Indeed, prior research demonstrates that both can significantly affect the emotional well-being of a woman and her partner ${ }^{7}$. Women may also experience emo-tional states that are known causative fac-tors of sexual dysfunction, such as depres-sion, anxiety, and lowered self-esteem. Marital distress may arise following the diagnosis of infertility, and women who have had multiple, unsuccessful treat-ment attempts are known to be at an even greater risk of psychological distress ${ }^{8,}, 9$.

Depression, erectile dysfunction ${ }^{10}$, and relationship distress are common and can occur as direct result of female sexual dysfunction ${ }^{11}$.

Conclusion: Female sexual dysfunction has a definite role in infertility and if documented necessary interventions like psychotherapy, lubricants, targeted sexual therapy and pharmacological treatment can be undertaken for the females suffering from female sexual dysfunction along with infertility. Sometimes appropriate treatment of female sexual dysfunction can preclude the use of expensive \& unnecessary treatment for infertility wheather it is the cause or the effect to be determined in the infertile patients before treating the couple.

\section{References:}

1. Lyons RA, Djahanbakhch O, Saridogan E, et al. Peritoneal fluid, endo-metriosis, and ciliary beat frequency in the human fallopian tube. Lancet. 2002; 360:1221-1222.

2. Neimeh Tayebi1, Seyed Mojtaba Yassini Ardakani2; incidence and prevalence of the Sexual Dysfunctions in Infertile Women

3. Jindal UN, Dhall GI. Psychosexual Problems on infertile women in India. Int J Fertil 1996; 35:222-5.

4. Audu BM. Sexual dysfunction among infertile Nigerian women. J Obstet Gynecol.2002; 22:655-7. 
5. Jain K, Radhakrishnan G, Agrawal P. Infertility and psychosexual disorders: Relationship in infertile couples. Indian J Med Sci 2000; 54:1-7.

6. Ponholzer A, Roehlich M, Racz U, Temml C, Maderbacher S. Female Sexual Dysfunction in a healthy Austrian cohort: Prevalence and risk factors. Eur Urol 2003; 47:366-74.

7. Laumann E, Paik A, Rosen R. Sexual dysfunction in the United States: prevalence and predictors. JAMA. 1999; 281:537-544.

8. Mahlstedt PP. The psychological component of infertility. Fertil Steril. 1985; 43:335-346.
9. Boivin J, Takefman JE, Tulandi T, Brender W. Reactions to infertility based on extent of treatment failure. Fertil Steril. 1995; 63:801-807.

10. Shindel AW, Nelson CJ, Naughton CK, Ohebshalom M, Mulhall JP. Sexual function and quality of life in the male partner of infertile couples: prevalence and correlates of dysfunction. J Urol. 2008; 179:1056-1059.

11. Basson R, Berman J. Report on the international consensus development conference on female sexual dysfunction: Definition and classification. J Urol 2000; 163:688-893. 